\title{
Correction to: A genetic algorithm for finding realistic sea routes considering the weather
}

\author{
Stefan Kuhlemann ${ }^{1,2}\left(\mathbb{C}^{1} \cdot\right.$ Kevin Tierney $^{1}[$
}

Published online: 15 August 2020

(C) The Author(s) 2020

\section{Correction to: Journal of Heuristics (2020) https://doi.org/10.1007/s10732-020-09449-7}

The original version of this article has unfortunately contained an error in the Acknowledgement section. The correct Acknowledgement section is given below

\section{Acknowledgements}

Open Access funding provided by Projekt DEAL. This work is partially supported by Deutsche Forschungsgemeinschaft (DFG) Grant 346183302. We would like to thank Lukas Arendt, Tino Engelbrecht, and Stephan Volkmann for their contributions to a student project leading to this work. Furthermore, we thank the Paderborn Center for Parallel Computation (PC2) for the use of the OCuLUS cluster.

Publisher's Note Springer Nature remains neutral with regard to jurisdictional claims in published maps and institutional affiliations.

The original article can be found online at https://doi.org/10.1007/s10732-020-09449-7.

Stefan Kuhlemann

stefan.kuhlemann@uni-bielefeld.de

Kevin Tierney

kevin.tierney@uni-bielefeld.de

1 Universität Bielefeld, Universitätsstraße 25, 33615 Bielefeld, Germany

2 Universität Paderborn, Warburger Str. 100, 33098 Paderborn, Germany 